\title{
Combined Surgical and Prosthetic Management of Severely Atrophied Mandibular Ridge with Shallow Vestibule
}

\author{
Parameshwari $\mathrm{G}^{1}$, Anulekha Avinash $\mathrm{CK}^{2}$, J eevan Kumar $\mathrm{KA}^{3}$, Taruna $\mathrm{M}^{4}$
}

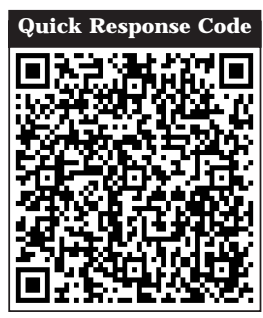

doi : 10.5866/2014.631645

${ }^{1}$ Postgraduate Student

${ }^{2}$ Reader

${ }^{4}$ Professor

Department of Prosthodontics

Kamineni Institute of Dental Sciences

India

${ }^{3}$ Professor

Department of Oral and Maxillofacial Surgery

Kamineni Institute of Dental Sciences

India

\section{Article Info:}

Received: April 11, 2014

Review Completed: May 10, 2014

Accepted: J une 9, 2014

Available Online: October, 2014 (www.nacd.in)

(c) NAD, 2014 - All rights reserved

Email for correspondence:

dr.parameshwari8@gmail.com

\begin{abstract}
:
Stability is considered as an utmost important factor while fabricating dentures for edentulous patient. But it is difficult to achieve satisfactory prosthetic results when mandibular alveolar ridge resorption is far advanced, as inadequatevestibular depth, high muscle and soft tissue attachments considerably reduce the stability of complete dentures.Preprosthetic surgery is recommended for shallow atrophied ridges to enhance the denture bearing area which intern increases stability of the dentures. Selection of the occlusal scheme also plays an important role to enhance the stability of the dentures in case of atrophied ridges. The present case report deals with the vestibuloplasty followed by construction of the dentures with lingualized occusal scheme.
\end{abstract}

Key words: Shallow vestibule, Vestibuloplasty, Surgical stent, Lingualized occlusion.

\section{INTRODUCTION:}

Bone resorption in the mandible and maxilla is a consequence of edentulism. Ridge atrophy poses a clinical challenge towards the fabrication of a successful prosthesis. As atrophy of the mandible progresses, the attachment of mucosa and muscle near the denture-bearing area exerts a greater influence on the retention and stability of the dentures. ${ }^{1}$ In addition, the amount and quality of fixed tissue over the denture-bearing area may be decreased. ${ }^{2}$ In such patients, preprosthetic surgery plays a significant contribution.

The intervention of vestibuloplasty in this particular case increased the surface area with respect to the denture bearing area. Lingualized occlusal scheme was apt which allowed centralization of vertical forces over the mandibular ridge, and provides additional stability to the 
denture. $^{3}$ This comprehensive surgical and prosthetic approach enhanced the stability of the mandibular denture and prevents further resorption of the existing bone where in the ridges were severely atrophied.

\section{CASE REPORT:}

A 53 year old female patient came to the department of prosthodontics for the replacement of missing upper and lower teeth. Intraoral examination revealed, eupulis fissuratum on the right upper cheek mucosa (Figure 1A), shallow mandibular vestibule with high muscle attachment (Figure 1B), and also oral sub mucous fibrosis was observed. History suggested, patient was previous denture wearer. OPG revealed insufficient remaining bone to place endosseous implants (F igure2). High muscle attachments serveto reduce the available denture bearing area and would undermine the denture stability. So it is virtually impossible for a lower denture to be retained solely by a prosthetic approach. A comprehensive treatment was planned after discussing the case with Department of Oral and Maxillofacial Surgery. Hence a "Ridge extension procedure" to gain the sufficient height for retention and stability was carried out followed by construction of dentures with lingualized occlusal scheme.

Surgical approach: Steroid therapy was implemented to treat oralsubmucousfibrosis. It was observed that the fibrosis and eupulis was resolved after 2 months of steroidal therapy (Figure3). Vestibuloplasty was performed all over the ridge after conditioning the oral mucosa.

Pre prosthetic mock surgery was performed on the diagnostic cast by scraping it to a depth of $7 \mathrm{~mm}$ (Figure 4A). A surgical stent was fabricated on it such that it allows an increase in vertical extension of denture flanges, wound healing and prevent relapse (Figure 4B).

Deepening of the vestibule without any addition of the bone is termed as "vestibuloplasty or sulcoplasty". The oral surgeon carried out the sulcus deepening by employing "Kazanjianvestibuloplasty technique (Figure 5A) with split thickness autogenous skin graft under general anesthesia and antibiotic coverage. ${ }^{4}$ This technique provides broader denture bearing area to support the denture
(Figure 5B). Later surgical stent was loaded with tissue conditioner and seated over the tissue to support the vestibuloplasty site. Splint was stabilized with circum mandibularwiring. Patient was recalled for every 1 week until the healing was observed. Once the satisfactory results achieved, a definitive prosthetic treatment was planned.

\section{Prosthetic approach: (step by step procedure)}

A definitive prosthetic intervention with lingualizedocclusal scheme was commenced after one month of surgery. Final I mpressions were made using an admix of three parts by weight of impression compound and seven parts by weight of tracing compound. J aw relations recorded and face bow transfer was done. 30 degree cusp designs for maxillary teeth (Figure 6A) and 0-degree cusp designs for mandibular teeth (Figure 6B) were selected to create lingualized occlusal scheme. Anterior try in was done and protrusive record was taken (Figure 6C). Articulator was programmed according to the protrusive record "The key feature is the arrangement of the posterior teeth so that only the maxillary palatal cusps occlude with shallow mandibular central fossae (Figure 6D). There is no contact between the mandibular buccal cusp and palatal maxillary cusps which might result in an inclined (non-axial) contact. Balancing and working contacts should occur only on the maxillary lingual cusps. ${ }^{5}$ Try in was carried out. Acrylization was done in conventional manner. Upper and lower complete dentures were given with lingualized occlusal scheme (Figure 7).

Patient was recalled after one week for the follow up. Mild intra oral adjustments were done. Dentures were evaluated for retention and stability and comfort. Patient was extremely satisfied.

\section{Discussion:}

Severe ridge atrophy results in increased interarch space, unstable and non retentive mandibular dentures with inability to withstand the masticatory forces. Various surgical and non surgical treatment options including pre-prosthetic surgeries followed by conventional complete denture prosthesis, implant supported prosthesis, special impression procedures. However, insufficient remaining bone and considering patients economical feasibility of the implant supported over denture was ruled out. 


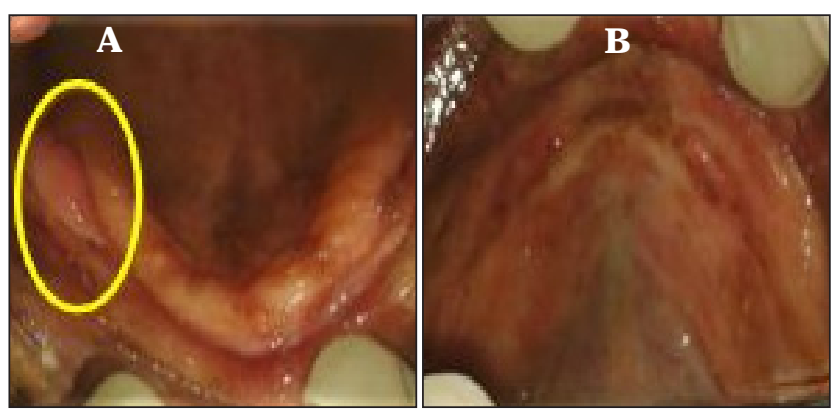

Figure 1: Preoperative intraoral view; 1A- Maxillary arch showing eupulis, $1 \mathrm{~B}$ - Mandibular arch showing shallow vestibule with high muscle attachment.

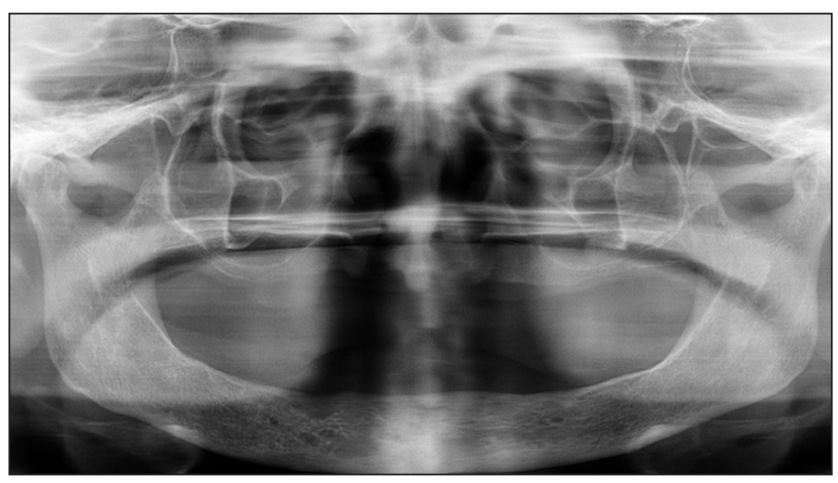

Figure 2: Preoperative OPG showing insufficient bone height

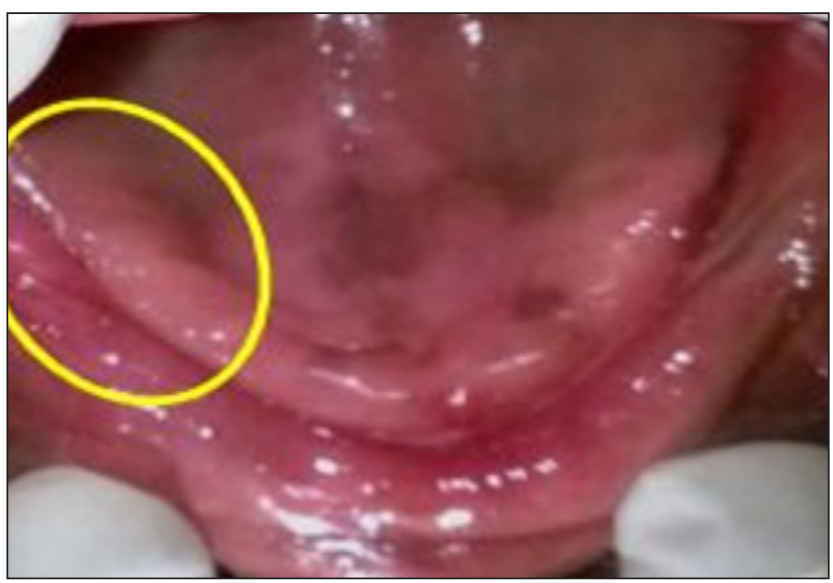

Figure 3: Maxillary arch showing healed eupilis.

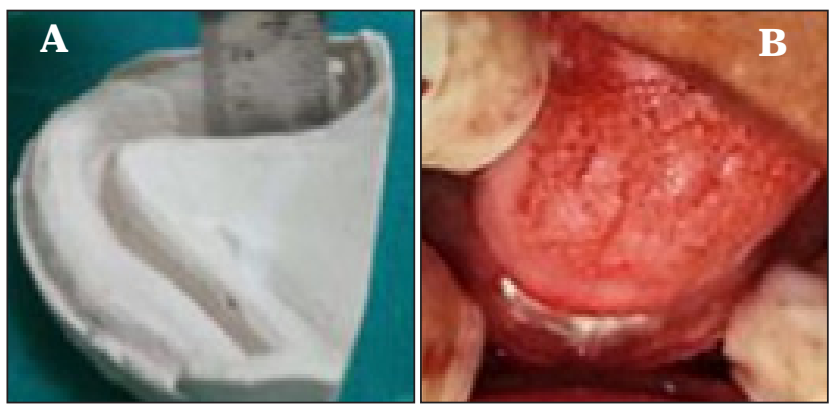

Figure 4: Surgical splint. 4A- Modified diagnostic cast to fabricate splint, 4B- Intra operative positioning of the surgical splint.

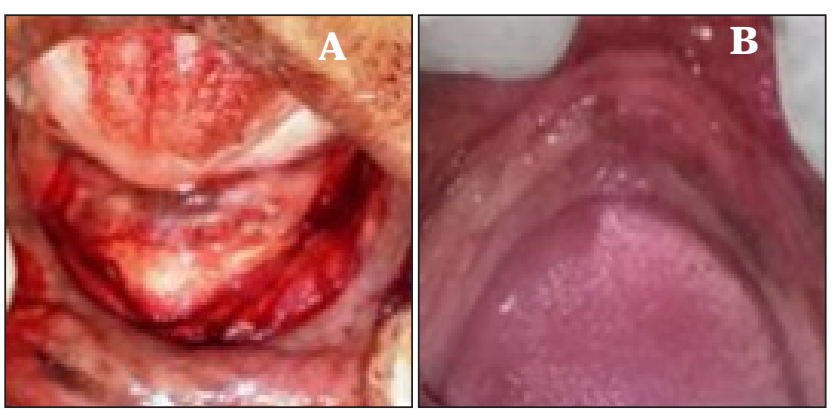

Figure 5: 5A- Vestibuloplasty performed all over the mandibular ridge; 5B- I mproved mandibular ridge height and width after vestibuloplasty

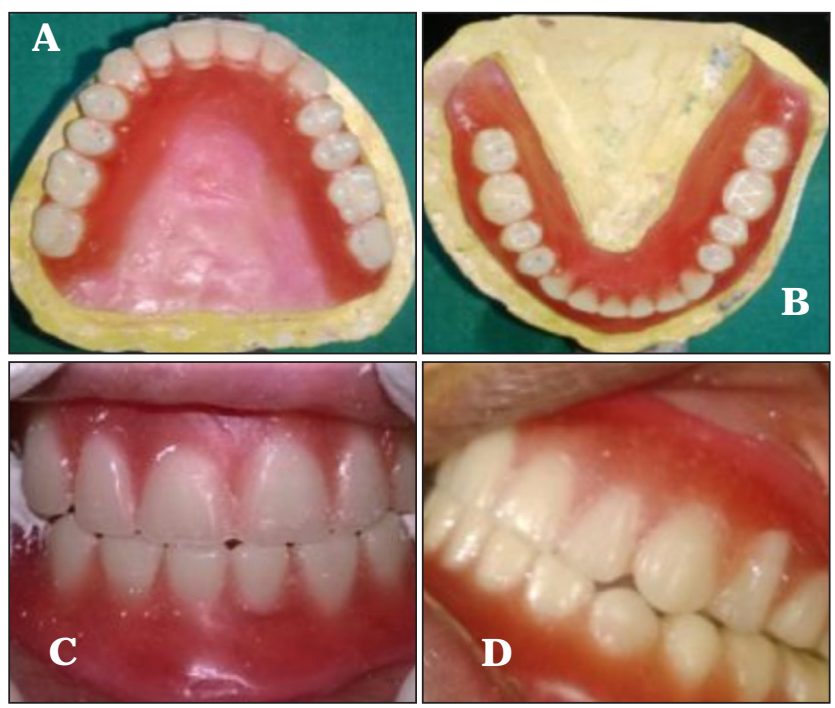

Figure 6: Llingualized occlusion. 6A- Maxillary trial denture showing anatomic posterior teeth, 6B-Mandibular trial denture showing monoplane posterior teeth, $6 \mathrm{C}$ - Protrusive bite, 6D- Buccal view showing cusp to fossa relationship.

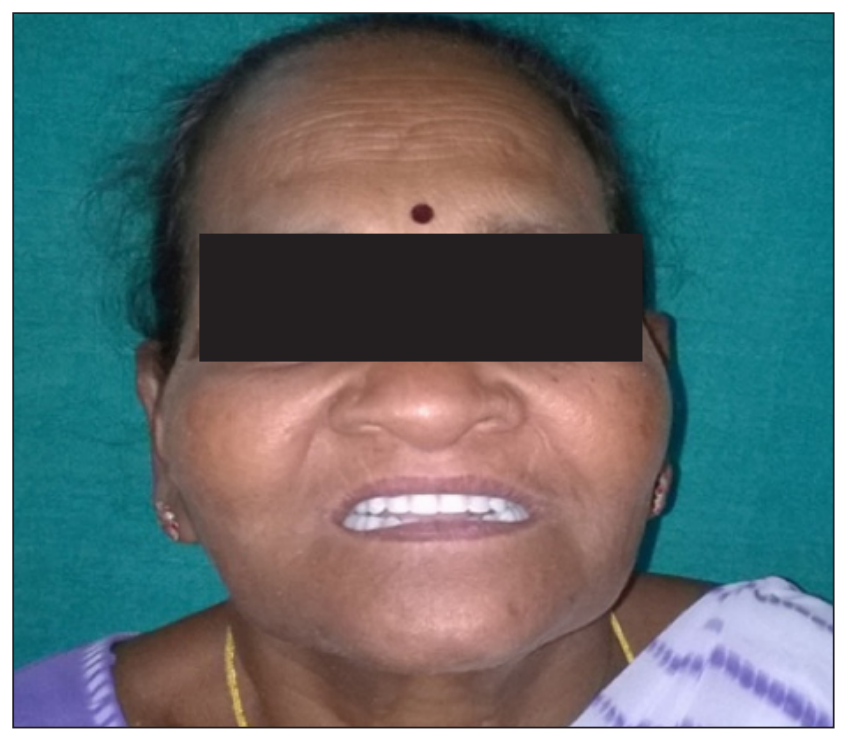

Figure7: Post insertion extra oral view. 
Next alternative treatment considered as vestibuloplasty because it provides an enlarged area of fixed tissue in the primary denture bearing area and to improve extensions in the area of denture flanges by removing the dislodging effect of muscle attachment in the denture bearing or vestibular area. ${ }^{6}$ Kazanjian vestibuloplasty technique was selected in this case as it causes comparatively less shrinkage \& relapse. ${ }^{7}$ Vestibular depth was significantly improved, which was still stable on subsequent follow up.

Admix impression technique described by McCord and Tyson was used to record the mandibular secondary impression. The philosophy behind that was a viscous admix of impression compound and tracing compound removes any soft tissue folds and smoothes them over the mandibular bone. ${ }^{8,9}$ This reduces the potential discomfort arising from the atrophic sandwich i.e. the creased mucosa lying between the denture base and mandibular bone.

Occlusal schemes play an important role to enhance the stability of the denture in case of atrophied ridges. In this particular case Lingualized occlusalscheme was apt because it maintains the esthetics and food penetration advantages of the anatomic form of the teeth while maintaining the mechanical freedom of the non anatomic form. ${ }^{5} 30$ degreecusp designs for maxillary teeth and 0-degree cusp designs for mandibular teeth were selected. ${ }^{10}$ This combination allows better centralization of the forces and better chewing efficiency. Maxillary lingual cusp and the lower fossa act as a mortar and pestle in chewing. Tipping the upper teeth buccally allows greater support to the facial muscles for improved esthetics and holds the buccal mucosa away from the occlusal plane, reducing cheek bite. It eliminates lateral forces which are deleterious to the undermined ridge and allows centralization of vertical forces over the mandibular ridge, apart from this it provides additional stability to the denture during parafunctional movements and prevents further resorption of the existing bone.

\section{CONCLUSION:}

Faulty prostheses can alter the character, condition and form of the underlying oral tissues. A thorough history, clinical examinations and sound knowledge about the possible treatment alternatives will help the prosthodontist to provide satisfactory complete denture prosthesis.

A multidisiplivary approach such as surgical and prosthodontic intervation provided a better outcome of the prosthesis with better stability, comfort, long term success of prosthesis in a patient with severe atrophied ridges.

\section{REFERENCES:}

1. Wright CR. Evaluation of the factors necessary to develop stability in mandibular dentures. J Prosthet Dent 2004; 92:509-518.

2. Fonseca RJ, Davis WH. Reconstructive preprosthetic oral and maxillofacial surgery. WB Saunders Co. Philadelphia 1986.

3. J aafar Abduo, DclinDent. Occlusal Schemes for Complete Dentures, A Systematic Review. Int J Prosthodont 2013; 26:26-33.

4. Sanders B, Starshak TJ . Vestibuloplasty In: starshak TJ, Sanders B, ed. Preprosthetic oral and maxill ofacial surgery. St. Louis, Toronto, London: Mosby, 1980; 165-213.

5. Becker CM, Swoope CC, Guckes AD. Lingualized occlusion for removable prosthodontics. J Prosthet Dent 1977; 38:601608.

6. Kotrianta J, Virtanen $\mathrm{K}$, Pernu $\mathrm{H}$ et al. Surgical and prosthetic treatment of the atrophic mandible. ScandJ Dent Res 1986; 94:146-153.

7. Mercier P, Cholewa J, Djockovic S, Masella R et al. Mandibular ridge augmentation and resorption with various visor procedures. J Oral Max Fac Surg 1982; 40:709-713.

8. McCord J F, Grant AA (2000) I mpression making. Br Dent J 188:484-492.

9. McCord J F, Tyson KW. A conservative prosthodontic option for the treatment of edentulous patients with atrophic (flat) mandibular ridges. Br Dent J 1997; 182:469-472.

10. Rodney D. Phoenix, Lingualized occlusion revisited, J Prosthet Dent 2010;104:342-346.

\section{Gain quick access to our journal online View our journal at wNM.nacd.in}

